\title{
Effect of MW and MW-Assisted Hot Air Roasting Process on Color Properties of Hazelnuts
}

\author{
Fatih Kalkan $^{1}$, Yvan Gariepy ${ }^{2}$, and Vijaya Raghavan ${ }^{2}$
}

\begin{abstract}
In this study, raw hazelnuts were roasted by microwave (MW) and microwave-assisted hot air under various roasting conditions. After roasting process, color properties of roasted hazelnuts such as $L$-value, $a$-value, $b$-value, total color change, Hue angle, and Chroma value were determined. MW experiments were done using a completely randomized factorial arrangement of two roasting types by three roasting times $(9,15,21$ minutes) by three roasting temperatures $\left(70,90,110^{\circ} \mathrm{C}\right)$ using three replications for each experiment. Significant differences were statistically found in $L$-value, $a$-value, $b$-value, total color change, Hue angle, Chroma value between MW and MW-assisted hot air roasting processes. Moreover, roasting time and roasting temperature mostly affected the parameters mentioned-above. Findings determined as experimentally may be of great importance regarding the MW applications in industrial roasting technologies.
\end{abstract}

Keywords-Color properties, hazelnut, microwave roasting, microwave assisted hot air roasting

\section{INTRODUCTION}

Turkey is the most important producer of hazelnut in the World with 660000 tones and followed by Italy, the United States, and Spain. The above mentioned amount corresponds to the percent 72 of the World's hazelnuts, which is produced in Turkey of which Black Sea Region produces almost all of it on more than 400000 ha [1].

Hazelnut is included in the class of tree nuts of which consists of the Brazil nut, cashews, almond, hazelnut, pecan, macadamia nut, pine nut, pistachio, and walnut. Tree nuts are segmented into two main groups, which are in-shell and shell tree nuts in the world market. In-shell nuts are the nuts that are produced and marketed with the shell intact. Shelled nuts are subject to processing such as blanching, dicing, coating, roasting, or grinding to get formulation of product needed or to increase consumer appeal [2].

Roasting process of hazelnuts is done owing to several aims, which one of them ensures to destroy toxins or allergens that may exist in it. The other aims are to

Fatih Kalkan ${ }^{1}$ is with the Biosystem Engineering Department, Agriculture Faculty, Yuzuncu Yil University, Van, 65080, Turkey

Yvan Gariepy ${ }^{2}$ is with the Department of Bioresource Engineering, Faculty of Agriculture and Environmental Studies, McGill University, Sainte-Anne-deBellevue, QC, Montreal H9X3V9 Canada.

Vijaya Raghavan ${ }^{2}$ is with the Department of Bioresource Engineering, Faculty of Agriculture and Environmental Studies, McGill University, SainteAnne-de-Bellevue, QC, Montreal H9X3V9 Canada. significantly enhance the color, flavor, texture, and appearance of the product $[3,2,4]$. Changes of color, flavor, and texture during roasting process are primarily related to drying and non-enzymatic browning [5,6,7]. Non-enzymatic browning is contributed to by heat treatments and it includes several reactions, which they are Maillard reaction, caramelisation, chemical oxidation of phenols, and maderisation [8]. Kim et al. [9] have reported that brown color in agricultural products increases due to Maillard reaction during roasting process [10,11]. Kim et al. [9] have also reported that the roasting process of small black soybean carried out at the higher roasting temperatures and roasting times caused an increase in browning degree for color.

Scientific report on the color properties of roasted hazelnuts by MW and MW-assisted hot air roasting is so scare, which the current study will contribute to the literature. We, therefore, applied MW and MW-assisted hot air on raw hazelnuts and examined them to determine $L$-value, $a$-value, $b$-value, total color change, Hue angle, and Chroma value.

\section{MATERIAL AND METHODS}

\section{Sample preparation}

Hazelnuts (Corylus avellana L.), which are called Jumbo Barcelona, were purchased from local market (Hazelnut Growers of Oregon, USA) as in-shell. They were cracked by hand, subsequent to the cracking process broken kernels were removed from the bulk. Before experiments, initial moisture content of hazelnuts was measured [12] and it was 5.7\% d.b.

Automated microwave assisted thermal system

The roasting process of hazelnuts was performed by using an automated MW-assisted thermal system designed in the postharvest technology laboratory, McDonald Campus, McGill University. The automated MW-assisted thermal system is capable of both MW and MW-assisted hot air roasting process. The microwave generator operates at $2450 \mathrm{MHz}$ with a variable power from 0 to $750 \mathrm{~W}$. The thermocouples, fiber optic cables and balance were connected to an Agilent 34970A data acquisition system and this system was also connected to a computer.

\section{Experimental procedure}

Microwave experiments

Microwave experiments were carried out using a completely randomized factorial arrangement of two roasting types by three roasting times by three roasting temperatures using three replications within each experiment. Hazelnut 
samples of $90 \pm 1 \mathrm{~g}$ were subjected to MW and MW-assisted hot air roasting processes during 9,15 , and 21 minutes of the roasting times of for 70,90 , and $110{ }^{\circ} \mathrm{C}$ of the roasting temperatures. Microwave power density was $1.1 \mathrm{~W} / \mathrm{g}$ of initial sample mass during all experiments. Samples were placed in single layer on the sample holder meshed which was attached to a balance. Temperature of hazelnuts was measured with the help of an optical fibre probe during roasting process.

\section{Color measurement}

Color measurements were done on the cheek areas of 12 kernels with skin for each roasting experiment by using Minolta Chromameter Model CR-300X (Minolta Co. Ltd., Japan), calibrated with a white standard tile. The three color coordinates of CIELAB (1976) are $L$ which ranges from black at 0 to white at 100, $a$ which measures green when it is negative and red when it is positive, and $b$ which measures blue when it is negative and yellow when it is positive. Hue angle, Chroma value, and total color change $(\Delta \mathrm{E})$ were calculated using the following equations:

$$
h^{o}=\arctan (b / a)
$$

$$
C=\left((a)^{2}+(b)^{2}\right)^{0.5}
$$

(2)

$$
\Delta E=\sqrt{(\Delta L)^{2}+(\Delta a)^{2}+(\Delta b)^{2}}
$$

$$
\Delta L=L-L_{\text {raw }}
$$

$$
\Delta a=a-a_{\text {raw }}
$$

$$
\Delta b=b-b_{\text {raw }}
$$

where subscript raw represents $L, a$, and $b$ values of unroasted hazelnut samples.

\section{RESULTS AND DISCUSSION}

$L$-value, $a$-value, $b$-value, Hue angle, and Chroma value of unroasted hazelnuts were determined as well as roasted hazelnuts, which are presented in Table I. These properties determined flashed on us to see what difference is between before roasting process and after roasting process.

TABLE I

PHYSICAL PROPERTIES OF UNROASTED HAZELNUTS

\begin{tabular}{lc}
\hline \hline Properties & Values \\
\hline$L$ & $48.18 \pm 0.91^{*}$ \\
$a$ & $17.42 \pm 1.24$ \\
$b$ & $24.28 \pm 1.30$ \\
Hue angle, $^{\circ}$ & $54.36 \pm 1.84$ \\
Chroma & $29.90 \pm 1.53$ \\
\hline \hline
\end{tabular}

"Mean \pm Standard deviation
Effect of MW and MW-assisted hot air roasting process on color parameters

Color parameters including $L$-value, $a$-value, $b$-value, $\Delta \mathrm{E}$, Hue angle and Chroma value are presented in Table II, and III. The roasting temperature statistically affected $L$-values at 9 minutes of the roasting time $(\mathrm{p}<0.05)$, whereas it did not statistically affect $L$-values at 15 and 21 minutes of the roasting times in MW roasting process. In MW-assisted hot air roasting process, $L$-values was statistically affected by the roasting temperature during 9 and 21 minutes of the roasting times $(\mathrm{p}<0.01)$, while it was not statistically affected by the roasting temperature at 15 minutes of the roasting time. $L$ values of roasted hazelnuts decreased with increasing of the roasting temperature from $90{ }^{\circ} \mathrm{C}$ to $110{ }^{\circ} \mathrm{C}$ in both $\mathrm{MW}$ and $\mathrm{MW}$-assisted hot air roasting process, varied between 47.09 and 43.79 for MW roasting process and between 47.03 and 36.46 for $\mathrm{MW}$-assisted hot air roasting process. $L$-values of roasted hazelnuts by MW roasting roaster were also higher than roasted hazelnuts by $\mathrm{MW}$-assisted hot air roaster $(\mathrm{p}<0.01)$. This trend may be contributed to by hot air applied with microwave. Since the $L$-value is a measure of the color in the light-dark axis, its decreasing means that the hazelnuts seem darker. It was also seen from the results that there was a trend in changing of $L$-values with increase in the roasting temperature compared to $a$-value and $b$-value. In a study carried out by Demir et al. [13], it was reported that $L$-value was the best represented by a first-order process, which supported our results. Values of $\Delta \mathrm{E}$, Hue angle, and Chroma were not affected by the roasting temperature in MW roasting process at all the roasting times, whereas they were statistically affected by the roasting temperature during 9 minutes $(\mathrm{p}<0.01, \mathrm{p}<0.05, \mathrm{p}<0.01), 15$ minutes $(\mathrm{p}<0.05$, $\mathrm{p}<0.05, \mathrm{p}<0.01$, ) and 21 minutes $(\mathrm{p}<0.01, \mathrm{p}<0.01, \mathrm{p}<0.01)$ of the roasting times in $\mathrm{MW}$-assisted hot air roasting process, respectively. Total color change symbolized with $\Delta \mathrm{E}$ is extensively used to characterize the variation of color in food processing. Values of $\Delta \mathrm{E}$ of roasted hazelnuts increased with increasing of the roasting temperature in both MW and MWassisted hot air roasting process during all the roasting times, which were lower levels in MW roasting process $(\mathrm{p}<0.01)$. The results obtained were in agreement with publish data by Bal et al. [14] and Dadali et al. [15].

\section{CONCLUSION}

$L$-values were lower in both MW and MW-assisted hot air roasting process at the higher roasting temperatures and the roasting times. A decrease trend was also obtained in $L$ values, Hue angles, and Chroma values with increasing of the roasting temperature and the roasting time in both MW and $\mathrm{MW}$-assisted hot air roasting process. Mentioned trend was not observed in $a$-values and $b$-values. Total color change markedly increased at the $110{ }^{\circ} \mathrm{C}$ of the roasting temperature during 21 minutes of the roasting time in MW-assisted hot air roasting process, which was 12.33 . 


\section{REFERENCES}

[1] FAO 2012, http://www.fao.org/ $(5$ 12, 2014).

[2] Demir, A.D., Baucour, P., Cronin, K., \& Abodayeh, K. (2003). Analysis of temperature variability during the thermal processing of hazelnuts. Innovative Food Science and Emerging Technologies, 4, 69-84. https://doi.org/10.1016/S1466-8564(02)00084-X

[3] Demir, A.D., \& Cronin, K. (2005). Modelling the kinetics of textural changes in hazelnuts during roasting. Simulation Modelling Practice and Theory, 13(2), 97-107. https://doi.org/10.1016/j.simpat.2003.11.007

[4] Wigotzki, M., Steinheart, H., \& Pashcke, A. (2000). Influence of varieties, storage and heat treatment on IgE-binding proteins in hazelnuts (Corylus avellana). Food and Agricultural Immunology, 12, 217-229. https://doi.org/10.1080/09540100050140759

[5] Ozdemir, M., Seyhan, F.G., Bakan, A.K., Ilter, S., Ozay, G., \& Devres, O. (2001). Analysis of internal browning of roasted hazelnuts. Food Chemistry, 73, 191-196. https://doi.org/10.1016/S0308-8146(00)00273-9

[6] Mayer, K.P. (1985). Infra-red roasting of nuts, particularly hazelnuts. Confectionary Production, 51, 313-316.

[7] Buckholz, L.L., Daun, H., \& Stier, E. (1980). Influence of roasting time on sensory attributes of fresh roasted peanuts. Journal of Food Science, $45,547-554$. https://doi.org/10.1111/j.1365-2621.1980.tb04098.x

[8] Manzocco, L., Calligaris, S., Mastrocola, D., Nicoli, M., \& Lerici, C. (2011). Review of nonenzymatic browning and antioxidant capacity in processed food. Trends in Food Science and Technology, 11, 340-346. https://doi.org/10.1016/S0924-2244(01)00014-0
[9] Kim, H.G., Kim, G.W., Oh, H., Yoo, S.Y., Kim, Y.O., \& Oh, M.S. (2011). Influence of roasting on the antioxidant activity of small black soybean (Glycine max L. Merrill). LWT - Food Science and Technology, 44, 992-998.

https://doi.org/10.1016/j.lwt.2010.12.011

[10] Lee, S., \& Lee, J. (2009). Effects of oven-drying, roasting, and explosive puffing process on isoflavone distributions in soybeans. Food Chemistry, $112(2), 316-320$.

https://doi.org/10.1016/j.foodchem.2008.05.065

[11] Nicoli, M.C., Anese, M., \& Parpinel, M. (1999). Influence of processing on the antioxidant properties of fruit and vegetables. Trends in Food Science and Technology, 10(3), 94-100. https://doi.org/10.1016/S0924-2244(99)00023-0

[12] Braga, G.C., Couto, S. M., Hara, T., \& Neto, J.T.P.A. (1999). Mechanical behavior of macadamia nut under compression loading. Journal of Agricultural Engineering Research, 72(3), 239-245. https://doi.org/10.1006/jaer.1998.0369

[13] Demir, A.D., Celayeta, J.M.F., Cronin, K., \& Abodayeh, K. (2002). Modelling of the kinetics of colour change in hazelnuts during air roasting. Journal of Food Engineering, 55, 283-292. https://doi.org/10.1016/S0260-8774(02)00103-6

[14] Bal, L.M., Kar, A., Satya S., \& Naik, S.N. (2011). Kinetics of colour change of bamboo shoot slices during microwave drying. International Journal of Food Science and Technology, 46, 827-833. https://doi.org/10.1111/j.1365-2621.2011.02553.x

[15] Dadali, G., Demirhan, E., \& Özbek, B. (2007). Color change kinetics of spinach undergoing microwave drying. Drying Technology, 25(10), 1713-1723.

https://doi.org/10.1080/07373930701590988

TABLE II

COLOR PROPERTIES IN MW AND MW-AsSisted Hot Air RoAsting PROCESSES

\begin{tabular}{|c|c|c|c|c|c|c|}
\hline \multirow[t]{2}{*}{ Color properties } & \multirow[t]{2}{*}{ Roasting type } & \multirow{2}{*}{$\begin{array}{l}\text { Time, } \\
\text { minute }\end{array}$} & \multicolumn{3}{|c|}{ Temperature, ${ }^{\circ} \mathrm{C}$} & \multirow[t]{2}{*}{ Mean } \\
\hline & & & 70 & 90 & 110 & \\
\hline \multirow{8}{*}{$L$} & \multirow{4}{*}{ MW } & 9 & $47.09 \pm 0.53 \mathrm{~d}^{\delta}$ & $45.98 \pm 0.73 \mathrm{de}$ & $45.22 \pm 0.40 \mathrm{e}$ & $46.09 a^{*}$ \\
\hline & & 15 & $45.23 \pm 1.14 \mathrm{~d}$ & $45.07 \pm 0.98 \mathrm{~d}$ & $44.58 \pm 0.42 \mathrm{~d}$ & $44.96 \mathrm{~b}$ \\
\hline & & 21 & $44.48 \pm 0.80 \mathrm{~d}$ & $44.01 \pm 1.18 \mathrm{~d}$ & $43.79 \pm 0.31 \mathrm{~d}$ & $44.10 \mathrm{c}$ \\
\hline & & Mean & 45.60 & 45.02 & 44.53 & $45.05 \mathrm{~A}^{\mathrm{f}}$ \\
\hline & \multirow{4}{*}{$\begin{array}{l}\text { MW-assisted hot } \\
\text { air }\end{array}$} & 9 & $47.03 \pm 0.74 \mathrm{~d}^{\delta}$ & $45.75 \pm 1.06 \mathrm{~d}$ & $43.78 \pm 0.02 \mathrm{e}$ & $45.52 \mathrm{a}^{*}$ \\
\hline & & 15 & $44.93 \pm 0.26 \mathrm{~d}$ & $43.65 \pm 0.34 \mathrm{de}$ & $42.87 \pm 1.44 \mathrm{e}$ & $43.82 \mathrm{~b}$ \\
\hline & & 21 & $44.07 \pm 0.15 \mathrm{~d}$ & $42.84 \pm 1.26 \mathrm{~d}$ & $39.46 \pm 0.99 \mathrm{e}$ & $42.12 \mathrm{c}$ \\
\hline & & Mean & 45.34 & 44.08 & 42.03 & $43.82 \mathrm{~B}$ \\
\hline \multirow{8}{*}{$a$} & \multirow{4}{*}{ MW } & 9 & $17.58 \pm 0.27 \mathrm{~d}^{\delta}$ & $17.58 \pm 0.34 \mathrm{~d}$ & $17.78 \pm 0.06 \mathrm{~d}$ & $17.64 a^{*}$ \\
\hline & & 15 & $17.27 \pm 0.09 \mathrm{~d}$ & $16.98 \pm 0.31 \mathrm{~d}$ & $17.66 \pm 0.35 \mathrm{~d}$ & $17.30 \mathrm{~b}$ \\
\hline & & 21 & $17.25 \pm 0.33 \mathrm{~d}$ & $17.21 \pm 0.12 \mathrm{~d}$ & $17.51 \pm 0.21 \mathrm{~d}$ & $17.32 \mathrm{~b}$ \\
\hline & & Mean & 17.36 & 17.25 & 17.65 & $17.42 \mathrm{~A}^{£}$ \\
\hline & \multirow{4}{*}{$\begin{array}{l}\text { MW-assisted hot } \\
\text { air }\end{array}$} & 9 & $17.28 \pm 0.45 \mathrm{~d}^{\delta}$ & $17.31 \pm 0.15 \mathrm{~d}$ & $17.05 \pm 0.23 \mathrm{~d}$ & $17.21 \mathrm{a}^{*}$ \\
\hline & & 15 & $17.22 \pm 0.09 \mathrm{~d}$ & $17.30 \pm 0.33 \mathrm{~d}$ & $17.19 \pm 0.04 \mathrm{~d}$ & $17.24 \mathrm{a}$ \\
\hline & & 21 & $17.10 \pm 0.65 \mathrm{~d}$ & $17.38 \pm 0.13 \mathrm{~d}$ & $16.16 \pm 0.18 \mathrm{e}$ & $16.88 \mathrm{a}$ \\
\hline & & Mean & 17.20 & 17.33 & 16.80 & 17.11B \\
\hline \multirow{8}{*}{$b$} & \multirow{4}{*}{ MW } & 9 & $23.41 \pm 0.34 \mathrm{~d}^{\delta}$ & $22.96 \pm 0.38 \mathrm{de}$ & $22.51 \pm 0.25 \mathrm{e}$ & $22.96 \mathrm{a}^{*}$ \\
\hline & & 15 & $22.35 \pm 0.83 \mathrm{~d}$ & $21.81 \pm 0.81 \mathrm{~d}$ & $21.39 \pm 0.86 \mathrm{~d}$ & $21.85 b$ \\
\hline & & 21 & $21.00 \pm 0.66 \mathrm{~d}$ & $20.75 \pm 1.01 \mathrm{~d}$ & $20.64 \pm 0.59 \mathrm{~d}$ & $20.80 \mathrm{c}$ \\
\hline & & Mean & 22.25 & 21.84 & 21.51 & $21.87 \mathrm{~A}^{\mathrm{f}}$ \\
\hline & \multirow{4}{*}{$\begin{array}{l}\text { MW-assisted hot } \\
\text { air }\end{array}$} & 9 & $23.04 \pm 0.47 \mathrm{~d}^{\delta}$ & $22.27 \pm 0.78 \mathrm{~d}$ & $20.43 \pm 0.08 \mathrm{e}$ & $21.91 a^{*}$ \\
\hline & & 15 & $21.91 \pm 0.26 \mathrm{~d}$ & $20.81 \pm 0.29 \mathrm{~d}$ & $19.36 \pm 0.99 \mathrm{e}$ & $20.69 b$ \\
\hline & & 21 & $21.03 \pm 0.22 \mathrm{~d}$ & $19.83 \pm 0.51 \mathrm{e}$ & $15.97 \pm 0.41 \mathrm{f}$ & $18.94 \mathrm{c}$ \\
\hline & & Mean & 21.99 & 20.97 & 18.58 & $20.52 \mathrm{~B}$ \\
\hline
\end{tabular}

Mean \pm Standard deviation. ${ }^{[*]}$ Means in the same column followed by the same lowercase letter are not significantly different $(\mathrm{p}<0.01)$ by Duncan's multiple range test. ${ }^{[\delta]}$ Means in the same row followed by the same lowercase letter are not significantly different $(\mathrm{p}<0.01)$ by Duncan's multiple range test. ${ }^{\left[{ }_{1}\right]}$ Means in the same column followed by the same uppercase letter are not significantly different $(\mathrm{p}<0.01)$ by Duncan's multiple range test. 
TABLE III

COLOR PRoperties In Mw AND MW-AsSisted Hot AiR ROASTING PROCESSES

\begin{tabular}{|c|c|c|c|c|c|c|}
\hline \multirow[t]{2}{*}{ Color properties } & \multirow[t]{2}{*}{ Roasting type } & \multirow{2}{*}{$\begin{array}{l}\text { Time, } \\
\text { minute }\end{array}$} & \multicolumn{3}{|c|}{ Temperature, ${ }^{\circ} \mathrm{C}$} & \multirow[t]{2}{*}{ Mean } \\
\hline & & & 70 & 90 & 110 & \\
\hline \multirow{8}{*}{$\Delta \mathrm{E}$} & \multirow{4}{*}{ MW } & 9 & $3.20 \pm 0.57 \mathrm{~d}^{\delta}$ & $4.17 \pm 0.73 d$ & $4.29 \pm 0.54 \mathrm{~d}$ & $3.89 \mathrm{a}^{*}$ \\
\hline & & 15 & $4.48 \pm 0.79 \mathrm{~d}$ & $5.02 \pm 1.14 \mathrm{~d}$ & $5.40 \pm 0.68 \mathrm{~d}$ & $4.96 \mathrm{~b}$ \\
\hline & & 21 & $5.58 \pm 1.06 \mathrm{~d}$ & $6.26 \pm 1.62 \mathrm{~d}$ & $6.13 \pm 0.50 \mathrm{~d}$ & $5.99 \mathrm{c}$ \\
\hline & & Iean & 4.42 & 5.15 & 5.27 & $4.95 \mathrm{~A}^{£}$ \\
\hline & \multirow{4}{*}{$\begin{array}{l}\text { MW-assisted hot } \\
\text { air }\end{array}$} & 9 & $4.05 \pm 0.14 \mathrm{~d}^{\delta}$ & $4.12 \pm 1.08 \mathrm{~d}$ & $6.35 \pm 0.23 \mathrm{e}$ & $4.84 \mathrm{a}^{*}$ \\
\hline & & 15 & $5.05 \pm 0.36 \mathrm{~d}$ & $6.38 \pm 0.52 \mathrm{de}$ & $7.80 \pm 1.41 \mathrm{e}$ & $6.41 \mathrm{~b}$ \\
\hline & & 21 & $5.58 \pm 0.42 \mathrm{~d}$ & $7.42 \pm 1.10 \mathrm{e}$ & $12.33 \pm 0.93 \mathrm{f}$ & $8.44 \mathrm{c}$ \\
\hline & & Mean & 4.89 & 5.97 & 8.83 & $6.56 \mathrm{~B}$ \\
\hline \multirow{8}{*}{ Hue angle } & \multirow{4}{*}{ MW } & 9 & $53.10 \pm 0.06 \mathrm{~d}^{\delta}$ & $52.56 \pm 0.97 \mathrm{~d}$ & $51.70 \pm 0.26 \mathrm{~d}$ & $52.45 \mathrm{a}^{*}$ \\
\hline & & 15 & $52.30 \pm 0.88 \mathrm{~d}$ & $52.09 \pm 1.12 \mathrm{~d}$ & $50.44 \pm 0.62 d$ & $51.61 \mathrm{~b}$ \\
\hline & & 21 & $50.60 \pm 0.69 \mathrm{~d}$ & $50.30 \pm 1.45 d$ & $49.68 \pm 0.48 d$ & $50.19 \mathrm{c}$ \\
\hline & & Tean & 52.00 & 51.65 & 50.60 & $51.42 \mathrm{~A}^{£}$ \\
\hline & \multirow{4}{*}{$\begin{array}{l}\text { MW-assisted hot } \\
\text { air }\end{array}$} & 9 & $53.12 \pm 1.21 \mathrm{~d}^{\delta}$ & $52.12 \pm 1.20 \mathrm{de}$ & $50.16 \pm 0.39 \mathrm{e}$ & $51.80 a^{*}$ \\
\hline & & 15 & $51.83 \pm 0.21 \mathrm{~d}$ & $50.27 \pm 0.71 d$ & $48.36 \pm 1.44 \mathrm{e}$ & $50.15 b$ \\
\hline & & 21 & $50.89 \pm 1.33 \mathrm{~d}$ & $48.76 \pm 0.95 \mathrm{e}$ & $44.66 \pm 0.42 \mathrm{f}$ & $48.10 \mathrm{c}$ \\
\hline & & Mean & 51.95 & 50.38 & 47.72 & $50.02 \mathrm{~B}$ \\
\hline \multirow{8}{*}{ Chroma } & \multirow{4}{*}{ MW } & 9 & $29.28 \pm 0.43 \mathrm{~d}^{\delta}$ & $28.92 \pm 0.14 \mathrm{~d}$ & $28.68 \pm 0.22 \mathrm{~d}$ & $28.96 a^{*}$ \\
\hline & & 15 & $28.25 \pm 0.71 \mathrm{~d}$ & $27.64 \pm 0.67 d$ & $27.74 \pm 0.88 \mathrm{~d}$ & $27.88 \mathrm{~b}$ \\
\hline & & 21 & $27.17 \pm 0.66 \mathrm{~d}$ & $26.96 \pm 0.76 \mathrm{~d}$ & $27.07 \pm 0.59 \mathrm{~d}$ & $27.07 \mathrm{c}$ \\
\hline & & Iean & 28.23 & 27.84 & 27.83 & $27.97 \mathrm{~A}^{ \pm}$ \\
\hline & \multirow{4}{*}{$\begin{array}{l}\text { MW-assisted hot } \\
\text { air }\end{array}$} & 9 & $28.81 \pm 0.25 \mathrm{~d}^{\delta}$ & $28.21 \pm 0.53 \mathrm{~d}$ & $26.61 \pm 0.17 \mathrm{e}$ & $27.87 a^{*}$ \\
\hline & & 15 & $27.86 \pm 0.25 \mathrm{~d}$ & $27.06 \pm 0.28 \mathrm{~d}$ & $25.89 \pm 0.76 \mathrm{e}$ & $26.94 \mathrm{~b}$ \\
\hline & & 21 & $27.11 \pm 0.26 \mathrm{~d}$ & $26.37 \pm 0.30 \mathrm{e}$ & $22.71 \pm 0.42 \mathrm{f}$ & $25.40 \mathrm{c}$ \\
\hline & & Mean & 27.93 & 27.21 & 25.07 & $26.74 \mathrm{~B}$ \\
\hline
\end{tabular}

Mean \pm Standard deviation. ${ }^{[*]}$ Means in the same column followed by the same lowercase letter are not significantly different $(p<0.01)$ by Duncan's multiple range test. ${ }^{[\delta]}$ Means in the same row followed by the same lowercase letter are not significantly different $(\mathrm{p}<0.01)$ by

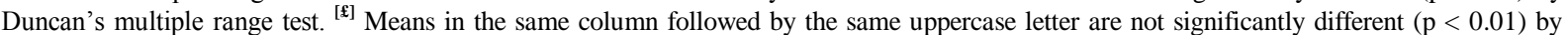
Duncan's multiple range test. 